\title{
The war on subsidence - Solutions for an event year and the role of the loss adjuster
}

Received (in revised form): 21st July, 2005

Tony Boobier BEng, CEng, FICE, FCILA, MCIM, MCIPS

has been working in the subsidence industry in excess of 25 years. Initially trained as a civil and structural engineer, he became a Fellow of the Institute of Chartered Loss Adjusters in 1991 and a Fellow of the Institution of Civil Engineers in 2002. In addition, he is a member of both the Chartered Institute of Supply and Procurement and the Chartered Institute of Marketing. During a wide-ranging career he has held major roles within insurers, loss adjusting companies and contractors, and is not only able to comment on the core technical aspects of this business area but also to provide a historical reflection on the topic. He has chaired and sits on the executive committee of several cross-industry forums and has presented to all-party committees on insurance industry matters.

\section{Abstract}

This paper tracks the background of the subsidence problem as far as the insurance industry is concerned, with specific attention given to the role of loss adjusters. It reviews the key drivers of organisational change within the subsidence industry, including the increased influence of supply chain management, its effects on consolidation of the supplier base and its linkage to change within the wider construction sector. Specifically, the paper considers organisational and structural changes within the industry in the context of a subsidence 'event year'. It also considers possible developments within the subsidence marketplace to offset the impact of a supply/demand imbalance among professional services.

\section{Keywords:}

subsidence, loss adjusters, insurance, supply chain management, constructing excellence, event year, subsidence forum, subsidence expert, competence

\section{INTRODUCTION - THE FIRST 20 YEARS}

Many building surveyors and other experienced building practitioners reasonably and correctly will argue that the subsidence of building foundations is not a new phenomenon. Examples of subsided buildings are prevalent among many Victorian and even older properties. Wooden framed buildings traditionally often show signs of distortion which some might say simply adds to their character, and sometimes also to their value. The insurance phenomenon of subsidence, however, is much more recent. Insurance cover for subsidence damage was first provided in the early 1970s, and to that extent the topic from an insurance point of view is merely 35 years old.

At the outset, insurance cover was principally intended for relatively catastrophic damage, with properties collapsing into major cavities 
Loss adjusters are impartial claims specialists paid by insurers following wash-out from drains. Unfortunately, this was not what the insurance wording actually stated, because the damage was simply referred to as a result of 'subsidence of the site', an expression now generally accepted as downwards movement of a property for reasons other than the self weight of the building itself. As many home insurance policies originated from mortgage requirements, with the lender having a vested interest in the equity value of the property, commercial pressures were to lead to the majority of insurers following the market trend.

As a result, the provision of subsidence cover became normal in domestic policies.

In the 1970s and 1980s, any relatively complex property insurance claim would be passed over by insurers to professionals known as loss adjusters. The role of an insurance loss adjuster in itself is an interesting one, originally dating back to the Great Fire of London in 1666. With the introduction of fire insurance shortly afterwards, independent surveyors and builders were relied upon for their expertise in dealing with claims. The word 'adjuster' appears to have been used first in 1941 with the founding of the 'Association of the Fire Loss Adjusters', which was a grouping of prominent experts who found themselves actively involved at a time when the nation was suffering from enormous fire damage as a result of bombing (Cato Carter, 1972).

Professional loss adjusters were granted their Charter by the Queen in 1961. The Chartered Institute of Loss Adjusters describes its members as 'impartial claims specialists...paid for by the insurance company who rely on them to check claims for quality, description and pricing' (www.cila.co.uk).

The uncertainty of the exact meaning of subsidence damage within the insurance context in the early 1970s and how to investigate the problem were compounded by the now-infamous summer of 1976. Extreme weather led to wide-scale drought in the South-East of England, with clay beneath the foundations shrinking dramatically and structural damage occurring. Large numbers of claims were made, passed by insurers to loss adjusters to handle, effectively creating an entirely new 'industry' which still exists and is worth by today's values in excess of $£ 500 \mathrm{~m}$ in repair costs each year.

\section{EARLY PROCESSES FOR HANDLING SUBSIDENCE CLAIMS}

Better understanding throughout the 1970s and early 1980s led to improvements in subsidence handling techniques but, equally importantly, in the more precise application of policy wording. This in turn led to greater and better investigation processes, leading to greater understanding of the causes of damage (and whether covered by the policy) and what needed to be done by way of repair. This process came to be known as the 'claims value chain' (Figure 1).

Loss adjusting companies were also continually developing their competence in this specific product area. As a result, there was an influx of surveyors, engineers and other building professionals into the subsidence industry, many supplementing their building knowledge and qualifications with additional insurance knowledge and understanding of 


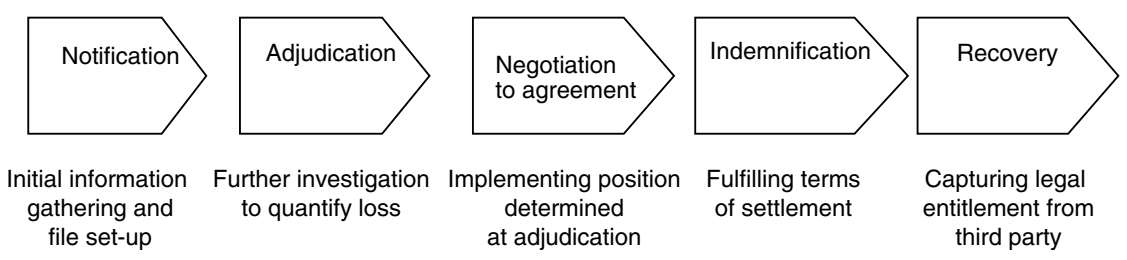

Figure 1: Claims value chain

the application of the insurance 'contract', also known as the 'insurance policy'.

One critical factor in insurance decision making was the age of the damage and whether it predated the insurance policy coming into operation. If so, pre-inception damage (as it became known) needed to be referred to the previous insurer, often causing delay and yet further inconvenience to the home owner. In many cases, the investigation would be duplicated by the current and previous insurers, and disagreements would arise as to the cause of damage, the timing and what proportion of repair fell for consideration under respective policies. Currently, market agreement between insurers now prevents this duplication taking place.

Where damage predated the purchase of a home, serious questions were also asked of the pre-purchase surveyor or the valuation surveyor in the case of a mortgage, both of whom were seen to owe a duty of care to both the homeowner and, inter alia, the insurer under what are known as 'subrogated rights'. Subrogated rights are acquired by insurers under the terms of the policy, whereby the insurer takes on the right and entitlements of the policyholder to recover money from any negligent third party.

A series of landmark cases permitted the recovery of money by insurers from negligent surveyors and valuers, even where damage was relatively modest but had an adverse impact on the value of a home. As a consequence, prudent building professionals increasingly took what can be best described as a cautious approach to any degree of damage.

The net effect of this 'cautious approach' was one of increased claims numbers for relatively minor damage, a series of disproportionate remedies arising (for example, underpinning where there was only superficial or relatively negligible damage), blight on homes which had subsided and were virtually unsellable and an overall aura of increased customer dissatisfaction. The dry summers of the mid-1980s further exacerbated the problem. With claims costs soaring and customer satisfaction falling, difficult questions started to be asked of those serving the subsidence industry. It was time for change.

\section{A SHIFT OF EMPHASIS FROM TRADITIONAL LOSS ADJUSTING}

In the mid-1980s, many loss adjusters, including those with an understanding of building construction, had already started to take professional advice from structural engineers, these engineers usually operating on a subcontract basis. On reflection it is curious that the subsidence industry started to rely on structural engineers rather than building surveyors. The principal argument was that subsidence is a form 


\section{Project managed subsidence revolutionised the industry}

of foundation failure, and that the remedy of failed foundation rested more in the engineering domain than in surveying.

Increasingly, adjusters who were working on a regular basis with the same engineers adopted coordinated approaches. Inevitably sharing of knowledge between engineers and adjusters started to occur, and the differences between the engineering and loss adjusting disciplines became less and less, although both remained in the overall solution. In 1989, one leading national insurer took the view that the loss adjuster could be cut out of the equation entirely and contracted directly with the engineering practices.

As far as subsidence was concerned, the loss adjusting industry was faced with a stark reality — change, or risk being marginalised. It is often said that the best form of defence is attack and, in the early 1990s, one major adjusting firm launched what has now become known as 'project managed subsidence', a process set to revolutionise the subsidence industry.

Project managed subsidence, in simple terms, is the loss adjusting practice replacing the engineer by doing the engineering 'in house'. In modern, supply chain parlance this would be described as 'vertical integration', provided through recruitment of better staff, in effect creating a new 'core competence'. Many other adjusting firms were also to follow that route, some more successfully than others.

The mid-1990s saw engineers and loss adjusters in direct competition for the same work. For those empowered with making the choice between engineers and adjusters, the new critical success factors were recognised as follows.

- Technical expertise: The ability to adopt the right technical solution.

- Cost of provision of the service.

- Capacity management: The ability to keep service standards regardless of volume.

- Customer management: The ability to have customer focus at an operational level.

- Supply chain management: The ability to marshal additional resources rationally including investigations and repairers.

- Technology: The ability to collect and use management information and electronic trading.

- Capability to innovate: By continually adding value and reducing expenses.

While some building surveying practices sought to enter the market, these were on the whole unsuccessful. The subsidence guide issued by the Institution of Structural Engineers (2000), however, did recognise that some building surveyors had the right expertise to deal with subsidence damage.

\section{'CONSTRUCTING EXCELLENCE' IN SUBSIDENCE}

It is occasionally forgotten that the subsidence industry sits as a discrete sector of the construction industry. In many ways the more major problems of the construction industry which existed in the late 1990s also 


\section{'Rethinking Construction' also applied to the subsidence industry}

were apparent within the subsidence area - ineffectiveness, delay, poor customer experience and rising costs.

It was perhaps natural for the subsidence industry to look at the wider construction marketplace for a solution. The template for change in the construction industry was laid down by Sir John Egan and others acting as a Construction Task Force for the Deputy Prime Minister. Their report of July 1998 entitled 'Rethinking Construction' was subsequently encapsulated in what was to become known as the 'Movement for Innovation M4i' (www.m4i.org.uk). Many of those same messages are also applicable to the subsidence sector. 'Rethinking Construction' identified the following five key drivers for improvement.

- Committed leadership: To understand the client's needs, focus the business and drive change through the organisation from the top.

- Focus on the customer: To educate, understand the customer's needs and measure performance and satisfaction.

- Integrate processes/teams: To plan, procure, deliver, manage performance and provide feedback.

- Quality-driven agenda: To target zero defects, seek 'right first time' and deliver on time/budget.

- Respect for people: To train, improve image, attract the best people, adopt a no-blame culture and provide fair remuneration.

From these five key drivers emerged four essential 'building blocks' of change as described below.

- Standardisation: The need for the creation of best practices, clarity of agreed processes, simplification and benchmarks to audit against.

- Partnering the supply chain: The selection and integration of key partners, working together with shared goals.

- Product development: The continuous improvement of the solution through the combined understanding of the supply partners.

- Implementation: The ability of organisations to work together in a structured way to manage change.

From these five key drivers and four building blocks were created a series of targets, based on the common mnemonic 'SMART' (specific, measurable, achievable, realistic, time-framed) (see Figure 2). In the subsidence arena, while the industry did not agree collectively to a set of improvements, it generally targeted the following areas of improvement.

- Reduced claims cost $\quad-10 \%$

- Reduced repair time $\quad-10 \%$

- Better predictability of repair time $+20 \%$

- Fewer defects $\quad-20 \%$

- Fewer accidents $\quad-20 \%$

- Better supplier productivity $\quad+10 \%$

- Better supplier profit $\quad+10 \%$ 


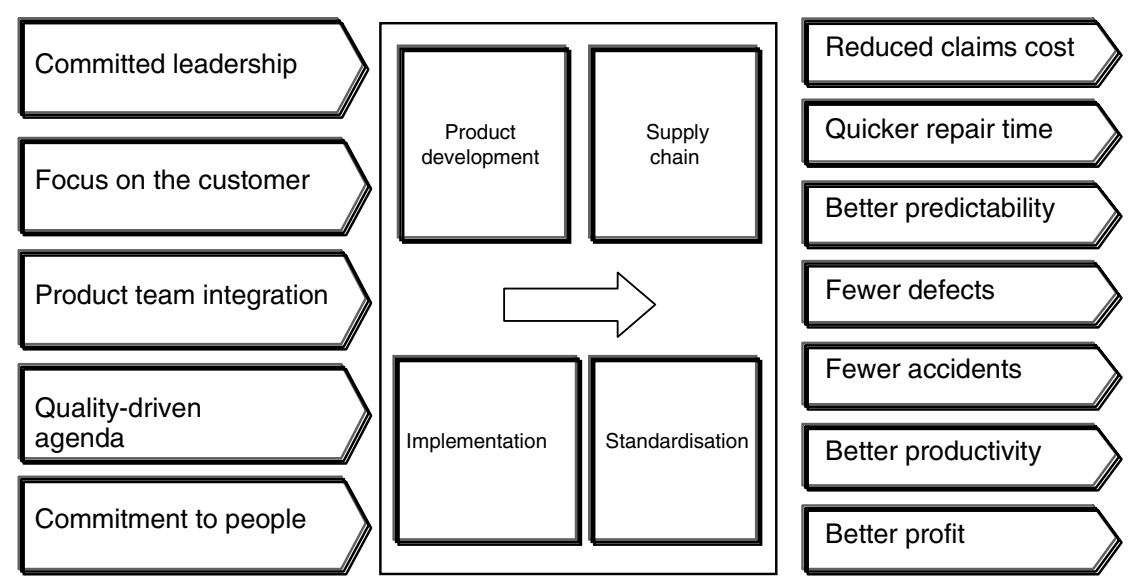

Figure 2: The improvement model

Step change improvement in service

\section{THE IMPACT OF A SUPPLY CHAIN APPROACH}

Supply chain processes have had a clear impact within the insurance sector over the past five years, and continue to do so, both within the subsidence arena but also across the wider spectrum of activities and increasingly including all property repair issues. Similar models have been adopted satisfactorily in the motor insurance sector, leading to what is generally recognised as a step change improvement in service. The key perceived impacts of supply chain management for insurers are listed below.

- Fewer suppliers who can provide scale solutions, particularly required for the scale purchasing organisations.

- Larger and more valuable contracts, requiring more care in the selection process but greater risk if the selection process goes wrong. As a result, procurement processes are more complex.

- Larger and longer duration contracts providing stronger negotiating power for purchasers.

- Fewer suppliers allowing fewer points of contact, with resultant relationships being cheaper to maintain.

- Increased move towards standardisation and therefore ultimately commoditisation of services.

- Ease of audit.

- Greater performance leverage and therefore an easier move to a consistent solution.

- Capacity management issues being delegated almost entirely to suppliers under the terms of the supply contract.

The key perceived issues of supply chain management for suppliers are listed below.

- Fewer clients to target, allowing and demanding more focused effort.

- Contracts becoming more valuable and, as a result, relationships becoming more important and more costly to maintain. 
- Risk of losing business for current providers becoming more critical.

- More complex and more expensive bidding process.

- Purchasing leverage of client forcing suppliers to find efficiencies, sometimes through leveraging their own supply chain and driving down the cost of their own suppliers and subcontractors.

- Performance oriented contracts forcing movement of organisations to performance culture, often by needing to incur IT costs to capture and report on service levels.

- Capacity problems transferred to the supplier.

Despite all these perceived problems on the part of the supplier, nevertheless there are always likely to be new entrants into what is a $£ 500 \mathrm{~m}$ marketplace, to compete with incumbent providers. While established providers arguably have a deeper understanding of the marketplace and more settled relationships, the barriers to entry for new providers are relatively low. The two greatest barriers to entry are intellectual capability, which can be acquired, and a suitable IT platform, which can be procured. Furthermore, new entrants tend to have fewer

New entrants bring high degree of focus legacy issues to resolve and often bring a high degree of focus.

The relationships between suppliers and clients, however, appear far from perfect in the subsidence arena, with less than optimum alignment between client and supplier. If there is an optimum position of client and supplier it is 'equal partners'. In reality there is little evidence of equality. Many suppliers still find themselves operating in a 'command and control' environment, within a very defined hierarchy. Many of these issues are also apparent in the wider construction industry (Association of British Insurers, 2000). The reasons for this in the subsidence market are partly legacy in nature but reflect the relatively small client base and the relatively large and disproportionate buying power. The key issues are outlined below.

\section{Alignment of culture}

There is increasing evidence that clients are beginning to choose suppliers who align with their cultures and values. The manner in which many key clients have reduced their supplier base, however, is often cost driven, creates tension and undermines cultural alignment issues.

\section{Implementation skills}

Many clients find it hard to communicate cultural requirements as a result of inadequate definition and suitable descriptors. As a result, clients accuse suppliers of being unwilling or unable to contribute adequately to the shared vision. Conversely, many suppliers appear frustrated at the lack of client organisations able to communicate adequately with them and their inability to participate fully.

\section{Cost of innovation}

There is a strong perceived link between IT and innovation. Generally, clients wish to be seen as innovators and want greater IT investment by suppliers, often in spite of uncertain work volumes and reduced margins. 
Contracts are usually bespoke and clientspecific for the same type of service

\section{Matching resources to volume}

There are always likely to be tensions where the volume of work available to pass to the supply chain is unpredictable, yet the burden of managing capacity is fully transferred. Clients usually provide indicative volumes but these are not contracted volumes.

\section{Procurement policy}

Increasingly, large organisations are using formal procurement processes and selection of suppliers is often based on a formal procurement/ evaluation process. Among the larger clients, selection criteria are relatively standardised but many suppliers complain that the standardised approach is irrelevant and disproportionate. One of the biggest grievances of suppliers is that of volume, in that, while anticipated workload is never 'promised', negotiations on price are usually related to indicative volumes which may or may not materialise.

\section{Irrelevant and inconsistent contracts}

There are seldom standard contractual forms used across the industry, instead these are often bespoke and client-specific. Suppliers providing the same service to different clients often will find quite different contractual wordings and service level requirements. The form of contract is often inappropriate to the perceived needs and drivers of the client.

\section{Cost of managing existing and future relationships}

Considerable emphasis remains on the informal relationship between suppliers and clients, either pre- or post-contract, with this often being very costly to maintain on the part of the supplier. The buying power of the client increasingly plays a fundamental part in this relationship.

\section{Effectiveness of operational delivery}

Increasingly more structured approaches to supply chain management are emerging, especially among the larger players, but the degree of integration between client and supplier teams remains piecemeal. Such integrated relationships where they occur take time to embed, leading to frustrations.

\section{Relevance of targets and measurement}

A high degree of commonality exists between clients when defining good or bad performance, usually described as the attainment of contracted service level agreements. Often there is also criticism that key performance indicators are not directly relevant and, where these exist, they are seldom measured properly.

\section{MANAGING SUBSIDENCE CAPACITY IN A DROUGHT YEAR}

Subsidence as a topic always has been notoriously difficult to plan for (Figure 3), a fact made worse by the uncertainty of what comprises a 


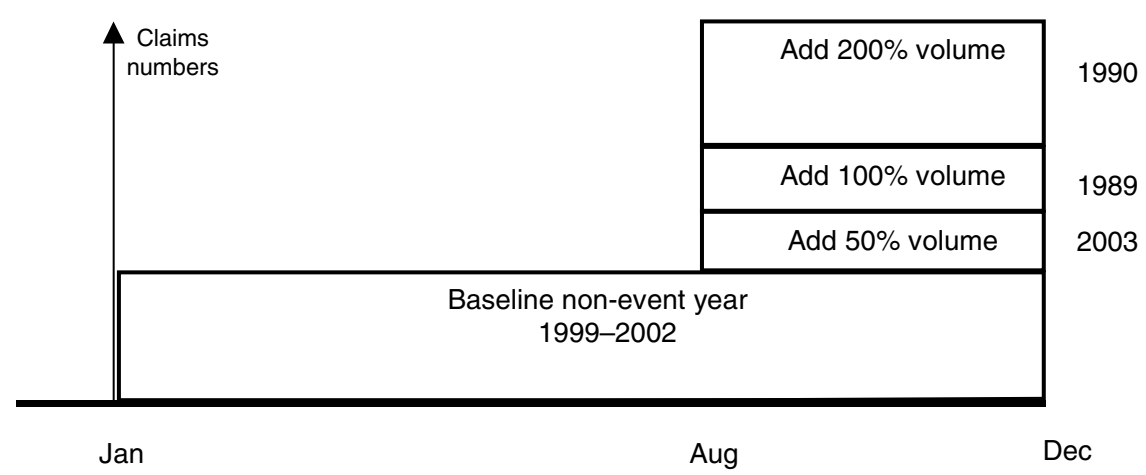

Figure 3: The effect of subsidence surges

\section{Homeowner attitude is a key factor}

'normal' year for the subsidence industry. Considerable research has been considered, a proportion undertaken, but overall this has been mainly inconclusive (Deakin, 2004).

Although there are some predictive indicators, typically soil moisture deficit within the ground itself, there is little certainty that there will be a surge of work until usually August of any year. Timing of notifications is often linked with damage being discovered by homeowners upon return from holiday, at exactly the same time that supplier staff themselves are also taking annual leave. The homeowner's attitude towards damage is also a key influencing factor, with media coverage being a prime catalyst for homeowner behaviour.

Supplier organisations are no longer permitted the luxury of surplus capacity of staff to meet a surge event. The ramping up of large volumes of work within a very short time, with little opportunity to predict damage or, indeed, a lack of robust prediction models, inevitably creates significant supply/demand imbalances in the supply chain. These imbalances have the potential to result in a return to the poor industrywide practices prevalent almost a decade ago, typically resulting in the following.

- Delays in progressing and resolving claims.

- Long delays in commencing repairs.

- Deterioration of damage as a result of mitigation being delayed, ie tree management.

- Overworked professionals not exerting adequate controls.

- Use of inexperienced staff dealing with complex structural problems.

- Supplier opportunism in the worst cases.

Some experts even consider that as a secondary, unplanned effect of procurement strategy in the subsidence marketplace, and with the buoyant construction industry elsewhere, there need not be a drought year for the industry to start to struggle. The overall loss of skilled experts from the wider pool of trained and experienced resources may mean that even moderately dry conditions could lead to a supply/demand imbalance of professional and other services. 


\section{Smaller firms and sole traders have become mainly subcontractors}

\section{ENGINEERS, SURVEYORS OR ADJUSTERS? THE EMERGING ROLE OF THE 'SUBSIDENCE EXPERT'}

Changes within the subsidence industry over the past decade have continued to affect the type and qualifications of those individuals from the professional team who provide the essential frontline resources to deal with subsidence claims. Current procurement policy increasingly calls for competent individuals and organisations, although often without any accepted definition across the industry. The sourcing of these competent staff has moved; initially they were loss adjusters, subsequently engineers and now increasingly they are a hybrid professional who can be described reasonably as a 'subsidence expert'. This 'expert' may or may not come from within loss adjusting practices or 'claims management' companies.

Larger clients are increasingly trading with larger suppliers, but where does this leave the smaller professional firm, or indeed the professional trading in isolation? There is some evidence that smaller firms and 'sole traders' remain in the picture, but principally as subcontractors to the larger firms. Capacity management of larger organisations appears to be predominantly satisfied by subcontract activity, with reliance on a myriad of smaller firms retaining the skills and competence required.

The procurement policy of larger clients has increasingly driven down the unit rate of providing the service. As a result, suppliers are passing on the 'pain' of these reduced rates to their subcontractors. The 'cash cow' which existed for many subsidence specialists in the 1980s and 1990s has well and truly gone. When juxtaposed against a relatively booming construction industry, particularly in the South-East of England, where coincidentally the great majority of subsidence claims also originate, serious problems are starting to emerge. The impact of the 2012 Olympics and the planned new homes in the South-East is bound to have an impact.

Organisations wishing to provide a service inevitably will need to pay premium salaries to attract the right people, pushing up the cost to provide the service, against a backdrop of rates being reduced by the client procurement policy. New operating models inevitably will need to emerge, probably through the development of competent independent traders acting collaboratively through a web-based network.

\section{MEASURING COMPETENCE IN SUBSIDENCE - THE SUBSIDENCE FORUM}

In 2005, a group of insurers and practitioners joined together to create what is now known as the Subsidence Forum. Collectively the group has created a Customer Charter and clear aims and objectives, the key one being that the subsidence industry speaks with a 'single voice' as far as practically possible (www.subsidenceforum.org.uk).

The Subsidence Forum also has a mission statement which is 'to raise the standard of subsidence handling in the UK'. Inevitably, this raises the issue of competence measurement and development in an industry which does not carry a recognised subsidence qualification. A debate has already started relative to the proper identification and recognition of subsidence 'experts'. It has identified key areas of competence — not just technical 
No room for complacency by established players but customer management and interpersonal skills, as far as these can be described and communicated reasonably. This is likely to be a challenging issue for the industry to contend with, but if widely accepted, one potential consequence could be a re-emergence of surveyors and other building professionals who have satisfied industry-wide competence requirements.

Assessment can be made of the number of full-time industry experts needed to service the subsidence marketplace fully, but there always will be an element of unpredictability. Future operating models are likely to comprise a core of full-time experts and a larger group of suitable 'experts' dealing with subsidence cases competently on a part-time basis, together with other income-earning activities. Such an arrangement would be flexible enough to meet the needs of the industry adequately without compromising quality or service.

The role of the loss adjuster acting as claims manager therefore could be two-fold. First, as the provider of full-time experts at the core of the solution. Secondly, as the manager of a larger group of outsourced providers operating on a subcontract basis, providing capacity to the marketplace. It is also entirely feasible for a loss adjuster/claims management company substantially or even entirely to outsource its field subsidence capability, providing only management and governance skills in a small core team.

Established subsidence suppliers such as loss adjusters should not be complacent in this marketplace. Procurement decisions will continue to be made based on competence, not on reputation or historical legacy, and the competition inevitably will be open to other specialist providers with a high level of skills and organisational competence.

\section{CONCLUSION}

Subsidence as a phenomenon is not new in terms of overall damage to buildings, but remains relatively new in terms of the cover provided for it by insurers. In the time that subsidence has been a topic within the insurance sector, there have been many changes, probably the most noticeable being the relatively recent emergence of supply chain management techniques. Supply chain techniques have created structure and consistency from a traditionally fragmented industry and provided a platform for innovation. Consolidation of both the client base and the supply base have led to increased purchasing and performance leverage.

For suppliers, margins for the provision of the service have tightened, to the point of becoming unattractive to those professionals who see better and more lucrative opportunities in other construction areas. These problems will become more acute in the South-East as a result of other construction activity.

Procurement policy has disenfranchised small traders, who increasingly have felt themselves marginalised. Despite the pressure on rates, however, many individual traders are still likely to continue to tolerate lower margins and continue to provide subcontracted services to the bigger players. The challenge therefore may well be one of how to provide a structure within which these smaller and individual traders can operate, including competence measurement. 
The role of the loss adjuster or claims manager potentially becomes one of being not only the manager of capacity but also of competency. Better understanding and communication of the competence required in time could re-open the door to individual engineers, surveyors and other suitably qualified building professionals to formally re-enter the subsidence marketplace as service providers. In such a model, a currently untapped, great potential resource could be utilised to satisfy any supply/demand imbalance. This model ironically would replicate in some ways the approach adopted by the subsidence industry in the early and mid-1980s, with a large network of individual suppliers working together in a structured environment, albeit future models would have greater governance, with technology providing the vital organisational glue. In the story of subsidence, perhaps the industry is about to enter another chapter of its history.

\section{References}

Cato Carter, E.F. (1972) The Real Business, William Clowes \& Sons, London, UK.

Institution of Structural Engineers (2000) Subsidence of Low Rise Buildings, 2nd edn, London, UK. Association of British Insurers (2000) Subsidence, a Review of Recent Research. General Insurance Research Report No. 9, London, UK.

Deakin, N. (2004) Paper presented to the Institution of Structural Engineers. Royal \& Sun Alliance, UK. 